\title{
Quantification and Analysis of Suspended Sediments Concentration Using Mobile and Static Acoustic Doppler Current Profiler Instruments
}

\author{
Angga Dwinovantyo, ${ }^{1}$ Henry M. Manik, ${ }^{2}$ Tri Prartono, ${ }^{2}$ and Susilohadi Susilohadi ${ }^{3}$ \\ ${ }^{1}$ Graduate School of Marine Technology, PMDSU Batch II, Bogor Agricultural University, IPB Darmaga Campus, \\ Bogor 16680, Indonesia \\ ${ }^{2}$ Department of Marine Science and Technology, Faculty of Fisheries and Marine Sciences, Bogor Agricultural University, \\ IPB Darmaga Campus, Bogor 16680, Indonesia \\ ${ }^{3}$ Marine Geological Institute, Ministry of Energy and Mineral Resources of the Republic of Indonesia, Jl. Dr. Djunjunan No. 236, \\ Bandung 40174, Indonesia
}

Correspondence should be addressed to Henry M. Manik; henrymanik@ipb.ac.id

Received 22 June 2017; Accepted 15 October 2017; Published 23 November 2017

Academic Editor: Kim M. Liew

Copyright (C) 2017 Angga Dwinovantyo et al. This is an open access article distributed under the Creative Commons Attribution License, which permits unrestricted use, distribution, and reproduction in any medium, provided the original work is properly cited.

\begin{abstract}
The application of Acoustic Doppler Current Profiler (ADCP) can be used not only for measuring ocean currents, but also for quantifying suspended sediment concentrations (SSC) from acoustic backscatter strength based on sonar principle. Suspended sediment has long been recognized as the largest sources of sea contaminant and must be considered as one of the important parameters in water quality of seawater. This research was to determine SSC from measured acoustic backscattered intensity of static and mobile ADCP. In this study, vertically mounted $400 \mathrm{kHz}$ and $750 \mathrm{kHz}$ static ADCP were deployed in Lembeh Strait, North Sulawesi. A mobile ADCP $307.2 \mathrm{kHz}$ was also mounted on the boat and moved to the predefined cross-section, accordingly. The linear regression analysis of echo intensity measured by ADCP and by direct measurement methods showed that ADCP is a reliable method to measure SSC with correlation coefficient $(r)$ 0.92. Higher SSC was observed in low water compared to that in high water and near port area compared to those in observed areas. All of this analysis showed that the combination of static and mobile ADCP methods produces reasonably good spatial and temporal data of SSC.
\end{abstract}

\section{Introduction}

Measurement of suspended sediment concentration (SSC) is important in the studies of sediment transport [1]. The measurement can be done in various ways, for example, by using conventional (laboratory analysis), optical, and acoustic methods. Conventional methods using gravimetric method in the laboratory have several disadvantages; for instance, it requires numerous water samples at each point and each depth of the observation station. Although this method is the most accurate for determining SSC to date, it still has limitation: it is unable to provide time series data and spatial characteristic of SSC because it requires continuous water sampling $[2,3]$. Moreover, this method is also relatively expensive and takes a long time of measurement process and sampling at all observation site, as well as optical method using laser in situ scattering and transmissometry [4]. To overcome this problem, the application of underwater acoustic technologies is used to quantify SSC, which can provide continuous and large coverage in greater detail of SSC data [5].

Utilization of acoustic instrument for determining SSC can be conducted using Acoustic Doppler Current Profiler (ADCP). This process uses extracted amplitudes from ADCP as echo intensity (EI) and converts it to SSC through calibration based on the sonar equation principle [6]. The calibration process was done by comparing the EI value to the laboratory-analyzed SSC at each layer of the water 


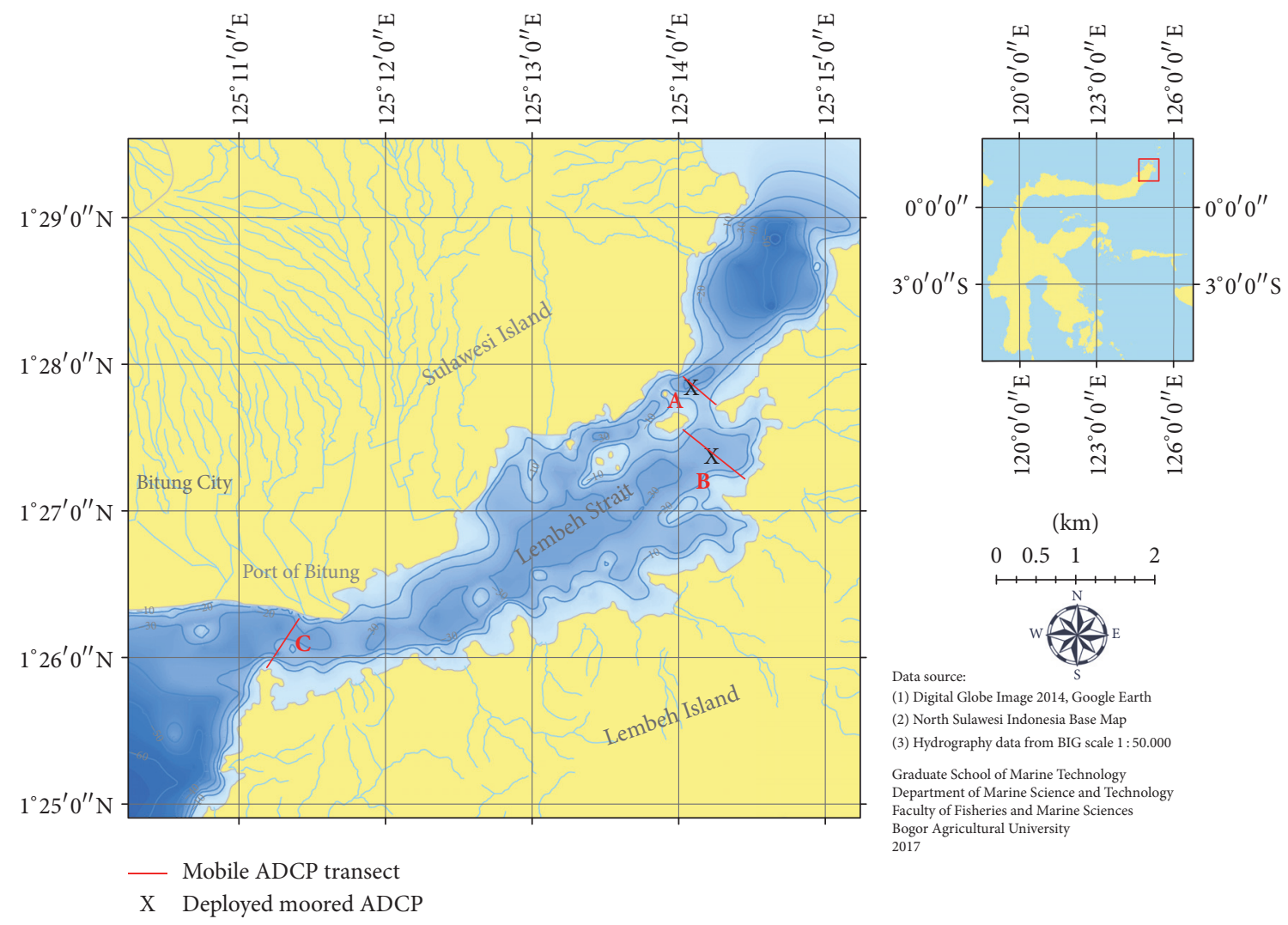

FIGURE 1: Research location in Lembeh Strait, North Sulawesi, Indonesia.

column using simple linear regression analysis. The slope and intercept obtained from linear equations were then used to convert EI values into SSC $\left(\mathrm{mg} \mathrm{L}^{-1}\right)$. There are two acquisition methods of ADCP, static (upward-looking) and mobile (downward-looking). Usually SSC is measured statically using ADCP [7]. However, this method has a disadvantage of not being able to see the spatial distribution of SSC in a particular area. The combination of static and mobile method will provide better and more detailed information of temporal and spatial resolution data of SSC [8].

The purpose of this study was to acquire and quantify the acoustic intensity of static and mobile ADCP to determine suspended sediment concentrations. In this study, we used three ADCP instruments with various frequencies in several areas in Lembeh Strait. This study also compared the results of suspended sediment concentrations obtained from ADCP and from laboratory results, as well as comparing SSC results from static and mobile ADCP methods. Specifically, the objectives of the study focused on the calibration methods of each ADCP instrument, the estimation of total suspended solids concentration from backscatter in static and mobile ADCP, and the comparison of the effect of tides on suspended sediment concentrations in oceanography aspect. This research is important because there has not been much research done on strait area with the influence of dominant tidal currents using the combination of static and mobile ADCP methods.

\section{Methods}

2.1. Time and Location. The collection of water samples and field data using ADCP instruments was conducted in Lembeh Strait, North Sulawesi, Indonesia (Figure 1), in April 2016. Data processing and analysis were done at Laboratory of Ocean Acoustic Data Computation and Sonar System, Marine Acoustic and Instrumentation Division, Department of Marine Science and Technology, Faculty of Fisheries and Marine Sciences, Bogor Agricultural University, Indonesia.

Static ADCP instruments were placed in two different locations: (A) shipping lane area $\left(1^{\circ} 28^{\prime} 2.8800^{\prime \prime} \mathrm{LU}-\right.$ $\left.125^{\circ} 14^{\prime} 6.3240^{\prime \prime} \mathrm{BT}\right)$ and (B) dive site area $\left(1^{\circ} 27^{\prime} 31.2240^{\prime \prime} \mathrm{LU}\right.$ $\left.125^{\circ} 14^{\prime} 2.1846^{\prime \prime} \mathrm{BT}\right)$, while mobile ADCP instrument was mounted on the boat and moved according to predefined cross-section: (A) shipping lane area, (B) dive site area, and (C) Port of Bitung area.

2.2. Tools and Materials. The tools and materials used in this research were static ADCP Nortek WAV 6579 with $400 \mathrm{kHz}$ frequency and SonTek Argonaut-XR with $750 \mathrm{kHz}$ frequency and mobile ADCP Teledyne RD Instruments Workhorse Mariner $307.2 \mathrm{kHz}$ frequency (Figure 2) equipped with Differential Global Positioning System (D-GPS) C-Nav and gyroscope motion sensors. Tides data were recorded using Tidemaster Tide Gauge. For the laboratory analysis of SSC, Whatman filter paper with $47 \mu \mathrm{m}$ diameter and vacuum 


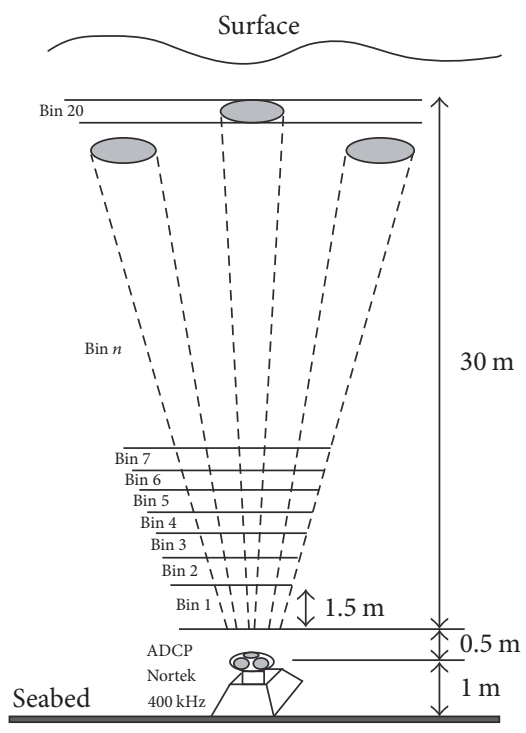

(a) Nortek WAV $6579400 \mathrm{kHz}$

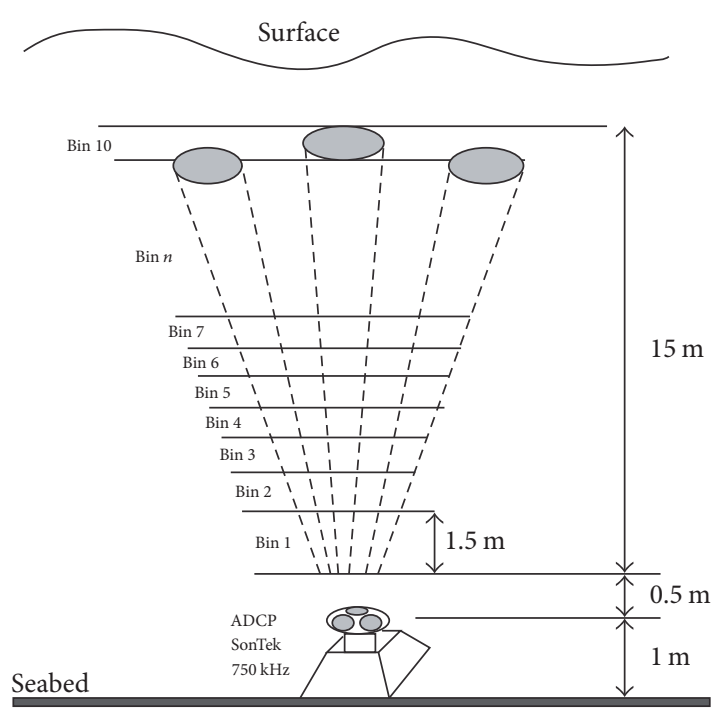

(b) SonTek Argonaut-XR $750 \mathrm{kHz}$

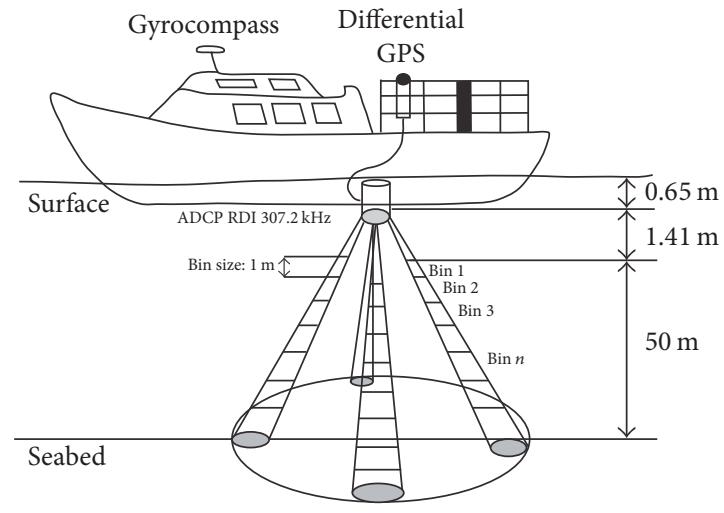

(c) RD Instruments Workhorse Mariner $307.2 \mathrm{kHz}$

Figure 2: ADCP setup: static ADCP (a) Nortek, (b) SonTek, and (c) Mobile ADCP RD Instrument.

pump were used. Water sample was taken using van Dorn Bottle Sampler. Horiba U-50 water quality checker was used as tool to measure temperature, salinity, and $\mathrm{pH}$.

\subsection{Data Acquisition, Processing, and Analysis}

2.3.1. Experiment Setup. Both static ADCP instruments were deployed on the seabed in two different places (Figure 1) from April 3, 2016, to April 23, 2016. Vertical profiling of SSC was made using upward-looking SonTek ADCP which was deployed at (A) shipping lane area, and Nortek ADCP was deployed at (B) dive site area. These static ADCPs were mounted $50 \mathrm{~cm}$ above the seabed with $1.5 \mathrm{~m}$ resolution, maximum depth 15, and $30 \mathrm{~m}$ for ADCP SonTek and ADCP Nortek, respectively, and were set to 20-minute recording interval. Mobile ADCP was placed $0.65 \mathrm{~m}$ below the water surface, with maximum detection depth $50 \mathrm{~m}$ and resolution $1 \mathrm{~m}$, and recorded at $1 \mathrm{~s}$ interval time. A previous research was conducted using an optical method of LISST-SL measuring device and was compared in stationary and moving mode to evaluate suspended sediment concentration [9].
Water sampling was conducted to measure the SSC concentration at several stations points along with the tidal time. One liter of water sample was taken using a van Dorn bottle; then it was stored in a clean polyethylene bottle. The samples were preserved by being kept in cold conditions in a closed place and hidden from sun. To compare the results between laboratory-analyzed and ADCP-based SSC, data were collected at the same depth and the same time, and to compare the results between static and mobile ADCP, data from mobile ADCP were collected at coordinate $1^{\circ} 28^{\prime} 2.8800^{\prime \prime} \mathrm{N}-125^{\circ} 14^{\prime} 6.3240^{\prime \prime} \mathrm{E}$ (location of SonTek ADCP) and at $1^{\circ} 27^{\prime} 31.2240^{\prime \prime} \mathrm{N}-125^{\circ} 14^{\prime} 2.1846^{\prime \prime} \mathrm{E}$ (location of Nortek $\mathrm{ADCP})$ at a particular water sampling time. All of the experiment setup is shown in Figure 3.

\subsection{Data Analysis}

2.4.1. Correction of Transmission Losses. Several corrections were necessary for converting raw data recorded by ADCP to SSC, for example, changes in transmission power due to distance, sound absorption by particles and chemical 


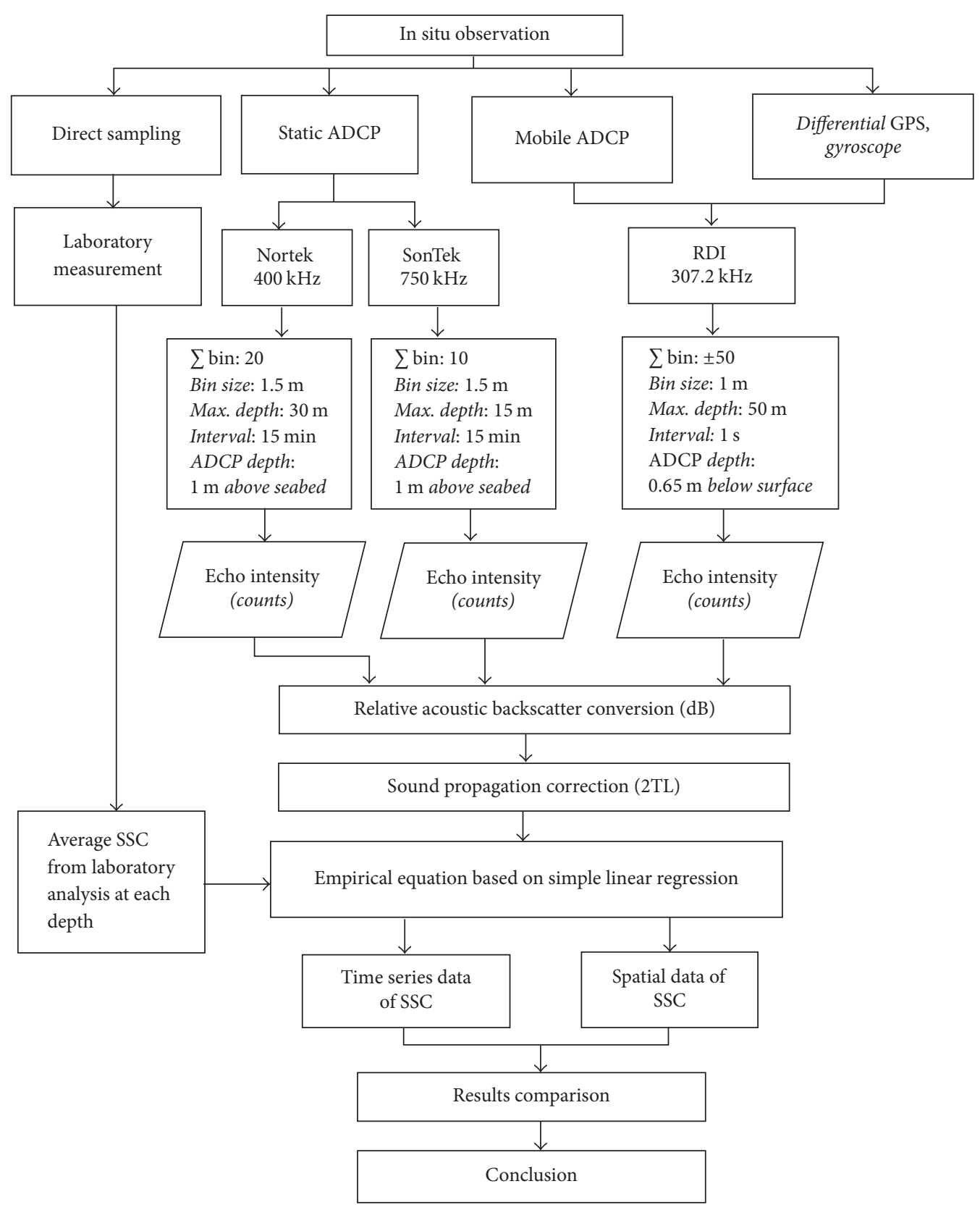

FIGURE 3: Research framework of data acquisition and processing for measuring suspended sediment concentration.

compounds in water column like magnesium sulphate and boric acid, and acoustic energy at near field. In the process of sound wave propagation, attenuation and geometrical spreading were primary factors needed to be removed due to suspended sediment or particles in the water column [10]. The problem was corrected by calculating the transmission loss (TL):

$$
\mathrm{TL}=20 \log _{10} R+\alpha R,
$$

where $\alpha$ is absorption coefficient $\left(\mathrm{dB} \mathrm{m}^{-1}\right)$ and $R$ is the range between ADCP transducer and the measured layer of bin $(\mathrm{m})$. ADCP instrument can differentiate and measure concentration of suspended sediment at different depths (bin). The measurement on this research was performed on each bin. TL values depended on frequency and SSC because of the ADCP frequency used and SSC encountered in this research. For frequency above $100 \mathrm{kHz}$, the movement of suspended sediment by sound generated from ADCP produced viscous drag which caused transmission energy loss. The distance between ADCP transducer and the bin was measured in $R$ for each depth:

$$
R=\frac{r+0.5 L_{\text {xmit }}}{\cos \theta} .
$$

From (2), $r$ value is the distance between transducer and the center of bin or half of the bin size, $L_{\mathrm{xmit}}$ is the 
transmission length of acoustic pulse, and $\theta$ is the angle of transducer. Absorption coefficient is highly dependent on temperature, salinity, $\mathrm{pH}$, and the presence of materials that can absorb sound waves. In addition, the absorption coefficient factor is also determined by the frequency of ADCP [11]. Absorption coefficient was calculated using the following formula:

$$
\begin{aligned}
\alpha= & 0.106 \frac{f_{1} f^{2}}{f_{1}^{2}+f^{2}} e^{(\mathrm{pH}-8) / 0.56} \\
& +0.52\left(1+\frac{T}{43}\right)\left(\frac{S}{35}\right) \frac{f_{2} f^{2}}{f_{2}^{2}+f^{2}} e^{-D / 6} \\
& +0.00049 f^{2} e^{-(T / 27+D / 17)}
\end{aligned}
$$

where $f$ is the frequency used in $\operatorname{ADCP}(\mathrm{kHz}), T$ is the average measured temperature in water column $\left({ }^{\circ} \mathrm{C}\right), D$ is the maximum depth $(\mathrm{m}), \mathrm{pH}$ is the average $\mathrm{pH}$, and $S$ is the average salinity in seawater (psu). The frequency of ADCP used in the research was the most important term because absorption coefficient depended on the frequency of acoustic instruments. Since the distribution and difference of $\mathrm{pH}$ in seawater were not much different, the $\mathrm{pH}$ value was not very important in this equation. Based on (3), $f_{1}$ and $f_{2}$ values indicate absorption by specific chemicals which were boric acid and magnesium sulphate, respectively, and are calculated as

$$
\begin{aligned}
& f_{1}=0.78 \sqrt{\frac{S}{35}} e^{T / 26} \\
& f_{2}=42 e^{T / 17}
\end{aligned}
$$

where $T$ is the temperature in water column $\left({ }^{\circ} \mathrm{C}\right)$ and $S$ is the salinity in seawater ( $\mathrm{psu}$ ). Both $f_{1}$ and $f_{2}$ depend on temperature, but only $f_{1}$, the boric acid frequency, depends on the salinity.

2.4.2. Echo Intensity to $d B$ Conversion. ADCP instruments received acoustic signal as echo intensity (count). $E_{r}$ symbol belongs to the noise in counts. The measured echo level values on transducer (RL) were calculated by reducing the echo intensity on each depth in count unit $(E)$ with constant of measured RSSI amplitude seen by the ADCP in the absence of the noise in counts unit $\left(E_{r}\right)$, and then the results were multiplied to echo intensity scale $\left(K_{c}\right)$. The echo intensity $(E)$ values must be much greater than the noise $\left(E_{r}\right)$ since $E_{r}$ may be affected by environmental noise $\left(E \gg E_{r}\right) . E_{r}$ value used in this research could be found by analyzing the signal received in each transducer [11] which was 40 counts. Echo level calculation was determined as

$$
\mathrm{RL}=K_{c}\left(E-E_{r}\right) .
$$

In RL value based on (5), $K_{c}$ value depends on temperature variation but is relatively constant in each depth of each site. $K_{c}$ values were calculated by

$$
K_{c}=\frac{127.3}{T_{e}+273},
$$

where $K_{c}$ is a factor used to convert the amplitude counts reported by the ADCP's receiver circuit to decibels ( $\mathrm{dB}$ per RSSI count), numerical value of 127.3 is the mean value of RSSI measurement from ADCP manufacturers, and $T_{e}$ is the temperature of the ADCP electronics $\left({ }^{\circ} \mathrm{C}\right)$ and add 273 to convert from degrees Celsius $\left({ }^{\circ} \mathrm{C}\right)$ to Kelvin $(\mathrm{K})$. Relative acoustic backscatter (RB) could be determined by adding (5) to (1). Since ADCP principle is active sonar, the transmission losses (2TL) were used in this formula. The RB values were calculated as follows:

$$
\mathrm{RB}=\mathrm{RL}+2 \mathrm{TL}
$$

The conversion process from echo intensity in counts to $\mathrm{dB}$ was simplified by

$$
E_{\mathrm{dB}}=K_{c}\left(E_{\text {count }}-E_{r}\right)+40 \log _{10} R+2 \alpha R .
$$

Equation (8) shows that $E_{\mathrm{dB}}$ depends on the TL. Based on the empirical formula, 1 count of static ADCP Nortek $400 \mathrm{kHz}$ is equivalent to $0.45 \mathrm{~dB}$, and 1 count of SonTek $750 \mathrm{kHz}$ is equivalent to $0.72 \mathrm{~dB}$. In mobile ADCP RDI $307.2 \mathrm{kHz}, 1$ count is equivalent to $0.43 \mathrm{~dB}$ [12-14]. This variation of conversion process depends on the instrument frequency.

The distance between the transducer and the first bin should be longer than the near field zone or in the far-field. The factor that can distinguish the far-field from near field is the critical range and written as follows [1]:

$$
R_{\mathrm{cr}}=\frac{\pi R_{0}}{4}
$$

where $R_{0}$ represents the distance of Rayleigh area $(\mathrm{m})$ which depends on the frequency used [12]. The near field area was determined by the calculation of the correction factor $(\psi)$ based on the equation [15] as follows:

$$
\psi=\frac{\left[1+1.35 Z+(2.5 Z)^{3.2}\right]}{\left[1.35 Z+(2.5 Z)^{3.2}\right]} .
$$

The contrast between $R_{\mathrm{cr}}$ and $R_{0}$ was symbolized as $Z$.

2.4.3. Conversion to Suspended Sediments Concentration (SSC). Data retrieval using ADCP over a given time span resulted in variation of relative acoustic backscatter (RB) values along with the movement of suspended particles and the amount of suspended sediment. The variation of echo intensity in $\mathrm{dB}\left(E_{\mathrm{dB}}\right)$ value in water column can be attributed to the amount of suspended sediment concentration (SSC) in $\mathrm{mg} \mathrm{L}^{-1}$. This relationship is based on the following sonar equation:

$$
\mathrm{SSC}=10^{\left(A+B \cdot E_{\mathrm{dB}}\right)} .
$$

The values of $A$ and $B$ were obtained from simple linear regression of laboratory-analyzed SSC. The SSC estimation was conducted on suspended sediment samples obtained through in situ measurement using ADCP and through gravimetric analysis. The depth for water sampling had to be 
at the same level as the bin depth observed by ADCP [16]. The comparison between laboratory-analyzed and ADCP-based SSC was then tested using the analysis of independent sample $t$-test with $95 \%$ confidence interval.

2.4.4. Laboratory Analysis of SSC. Water samples were taken from 30 different depths, starting from 1 until $30 \mathrm{~m}$ with $1 \mathrm{~m}$ interval by using van Dorn bottle. The amount of water sample was 1 liter and then stored in polyethylene bottles. The bottles were later put in a cooling box packed with ice cube $\left(<4^{\circ} \mathrm{C}\right)$ before being analyzed in the laboratory. This process was repeated 5 times in different water tidal conditions (from high water tide, ebb tide, and then low water tide). Filter paper with pore diameter $47 \mu \mathrm{m}$ was used to filter $200 \mathrm{~mL}$ of water $(C)$. Before the filtration process, the filter paper was dried at the temperature of $103-105^{\circ} \mathrm{C}$ for 1 hour, and then the paper was cooled in a desiccator and weighed $(B)$. After water filtration process, the filter paper plus residue was dried again for at least one hour at $103-105^{\circ} \mathrm{C}$, cooled in the desiccator, and weighed $(A)$. Direct SSC measurement $\left(\mathrm{mg} \mathrm{L}^{-1}\right)$ was calculated by [17]

$$
\operatorname{SSC}\left(\mathrm{mg} \mathrm{L}^{-1}\right)=\frac{(A-B) \times 1000}{C} \text {. }
$$

2.4.5. Comparison between Static and Mobile Method. In evaluating SSC measurement using ADCP, it is important to understand the comparison between the results of static and mobile method. Since frequency is the distinguishing factor between these two methods, verification process was required to evaluate the SSC results. The comparison areas were located at A (shipping lane area) and B (dive site area) because at those stations, the data acquisition was performed using both static and mobile ADCP. This process was done by taking the same time and coordinate of ensemble data from static and mobile ADCP. All mobile ADCP data were acquired at location A on April 10, 2016, and at location B on April 11, 2016. This mobile ADCP data was corrected from tidal condition and plotted using MATLAB.

\section{Results and Discussion}

During the field observation in static ADCP area, it was found that the seabed substrate consisted of mud and fine sand. Lembeh Strait had strong water currents, likely caused by tidal and bathymetry morphology. In Figure 4, it can be seen that the water condition near the bottom was categorized as turbid with visibility ranging from 5 to $10 \mathrm{~m}$. Based on several factors that have been described, the transmission losses correction factors (absorption and distance) became important because they were related to sound signal propagation. The factors affecting sound propagation recorded by ADCP were distance, medium, and coefficient of attenuation $[18,19]$.

3.1. Echo Intensity Conversion. Acoustic signal attenuation by suspended sediment $\left(\alpha_{s}\right)$ was divided into three factors: due to medium viscosity, scattering component, and diffraction caused by the loss of energy [20]. By substituting the study area environmental condition (temperature $(T)=28.55^{\circ} \mathrm{C}$,

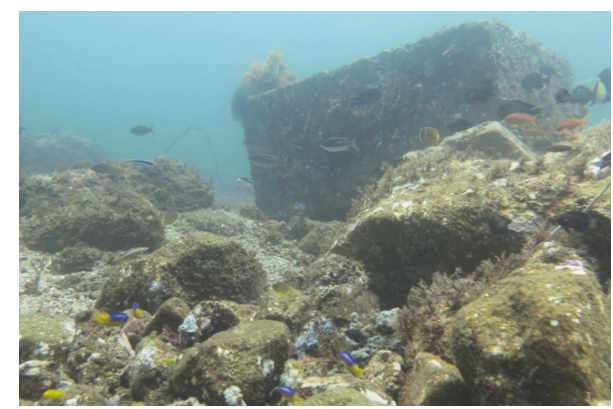

FIGURE 4: Conditions near the bottom in the deployed static ADCP area.

salinity $(S)=33.23 \mathrm{psu}$, and $\mathrm{pH}=8.13$ ) into (3), absorption coefficients $(\alpha)$ were determined as $0.0533 \mathrm{~dB} \mathrm{~m}^{-1}$ on ADCP Nortek $400 \mathrm{kHz}, 0.1676 \mathrm{~dB} \mathrm{~m}^{-1}$ on ADCP SonTek $750 \mathrm{kHz}$, and $0.0361 \mathrm{~dB} \mathrm{~m}^{-1}$ on ADCP RDI $307.2 \mathrm{kHz}$. The average sound speed of the ADCP device was $1538.98 \mathrm{~m} \mathrm{~s}^{-1}$ and has $20^{\circ}$ beam angle on ADCP Nortek and RDI and $25^{\circ}$ on ADCP SonTek. Each tool had different scale factors. The value of 1 count echo intensity was equivalent to $0.72 \mathrm{~dB}$ count $^{-1}$ on SonTek ADCP instrument; $0.4 \mathrm{~dB}$ count $^{-1}$ on the Nortek ADCP instrument; and $0.43 \mathrm{~dB}$ count $^{-1}$ on the $\mathrm{RD}$ Instrument. The results of echo intensity correction to the transmission losses were then converted into $\mathrm{dB}$ units with the result of the time series shown in Figure 5.

The backscattered values of Figure 5 indicate that the water column could be divided into three layers according to the backscattering strength: near surface, water column, and above bed. Backscattering from near the bottom was greater than that from the near surface and water column area. The color differences displayed on the echogram were the representation of the relative acoustic backscatter. Based on previous research [21], if the relative acoustic backscatter value had a high value then it was indicated that the observation area had high concentration of suspended sediment. There were various relative acoustic backscatter values obtained from each ADCP instrument. The relative acoustic backscatter values obtained from ADCP Nortek, SonTek, and RDI ranged between $53-89 \mathrm{~dB}, 60-95 \mathrm{~dB}$, and $58-85 \mathrm{~dB}$ on the near surface; 68-107 dB, 75-110 dB, and 85-98 dB in the water column; and $82-134 \mathrm{~dB}, 100-138 \mathrm{~dB}$, and $85-100 \mathrm{~dB}$ near the bottom of the water, respectively. The highest value was found at the depth of 25 to $30 \mathrm{~m}$. The cause of acoustic backscatter differences in Figure 5 was the presence of suspended sediments in the water column. The characteristic of acoustic backscatter might reflect those of the concentration of scatterers in water column such as suspended sediment. Stronger acoustic backscatter values were due to an indication of higher suspended sediment concentrations in the detected region and vice versa. In addition, the following observation depended on the ADCP's frequency used in the acquisition process. Despite this, the high acoustic backscatter near the bottom of water was indicated by the resuspension of fine fraction of suspended sediment which resulted in negligible variation of the backscattering strength. 
TABLE 1: Comparison of the results of simple linear regression analysis for three ADCP instruments used in the study. Each calibration process involved 50 data pairs at different tidal conditions in 8 hours during the ebb, flood, high water, and low water of tides.

\begin{tabular}{|c|c|c|c|c|c|}
\hline Method & ADCP instrument & $n$ & Slope & Intercept & $r$ \\
\hline \multirow{2}{*}{ Static } & Nortek $400 \mathrm{kHz}$ & 50 & 0.0392 & 1.4021 & 0.9457 \\
\hline & SonTek $750 \mathrm{kHz}$ & 50 & 0.0435 & 1.4639 & 0.9346 \\
\hline Mobile & RDI Workhorse $307.2 \mathrm{kHz}$ & 50 & 0.0202 & 1.6121 & 0.9226 \\
\hline
\end{tabular}

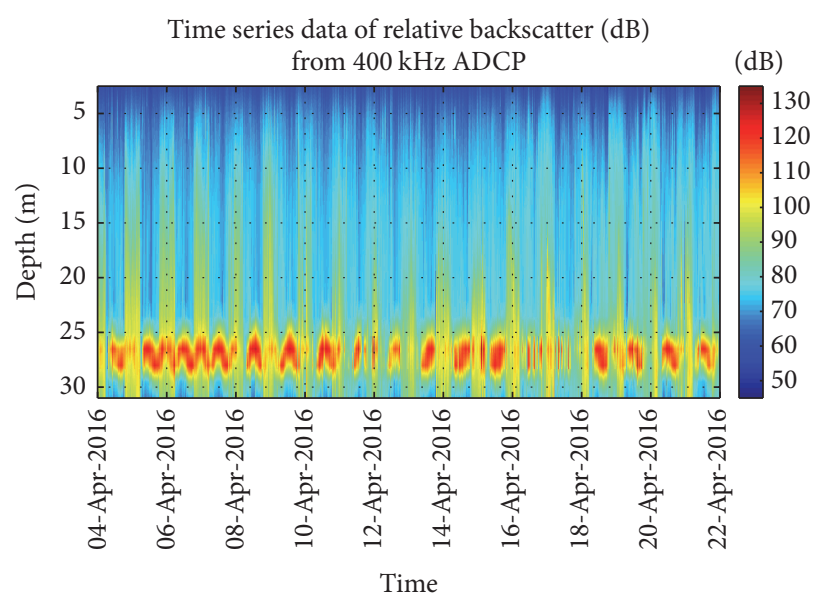

(a)

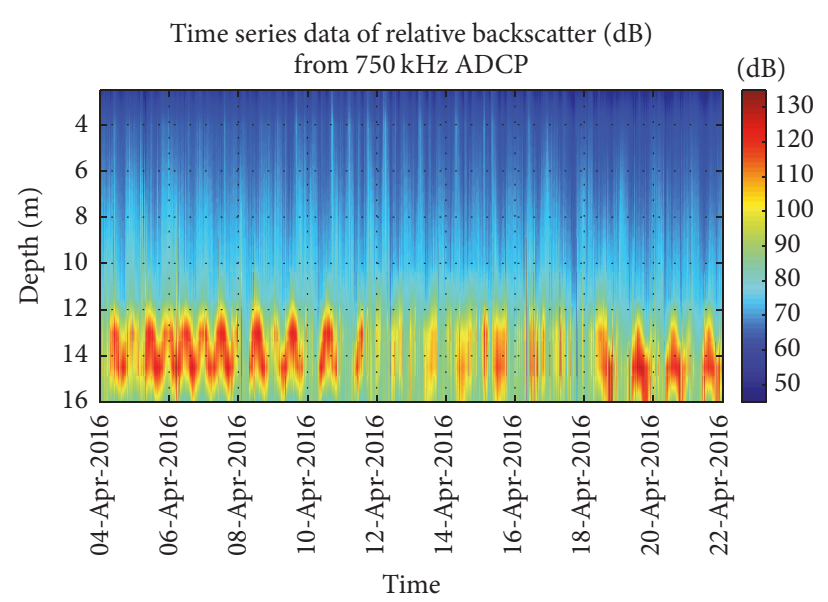

(b)

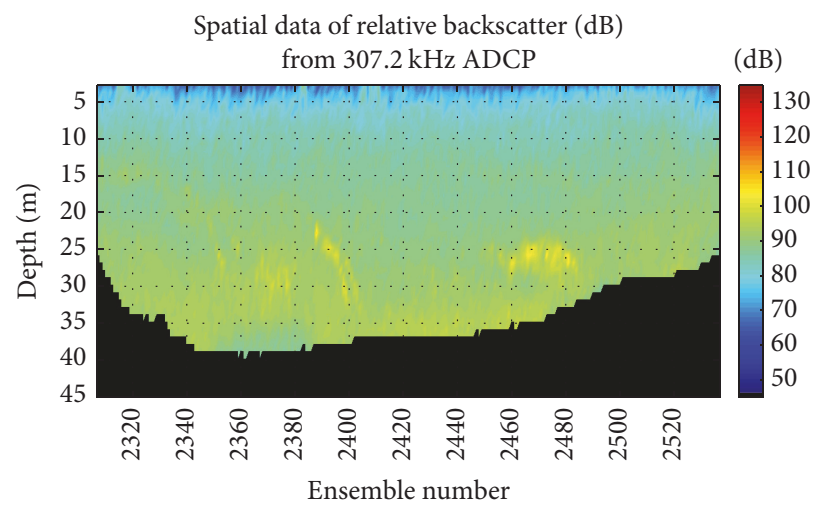

(c)

Figure 5: Conversion of echo intensity to relative acoustic backscatter from (a) Nortek, (b) SonTek, and (c) one of the sites near the Port of Bitung using RDI ADCP Instruments.

3.2. Calibration. Measured ADCP backscattered data were converted to SSC data using the laboratory data as calibration and linear regression analysis. SSC data attained from laboratory analysis were then compared to relative acoustic backscatter from ADCP at the same measurement depth. Simple linear regression was used for this analysis. Water sampling was conducted over the ebb, flood, high water, and low water of tidal condition at every one hour during observation. This calibration process was used to determine slope and intercept data, given at Table 1. Figure 6 illustrates a rather high correlation between acoustic backscatter and laboratory-analyzed SSC with all correlation coefficient $>0.9$ with each calibration process involving 50 data pairs.

The calibration results show that the relative acoustic backscatter values of ADCP were positively correlated to the laboratory-analyzed suspended sediment concentration. The slope and intercept values were later used to estimate the time series and spatial distribution of suspended sediment concentration. The relative acoustic backscatter values of each bin at all ensembles were then multiplied by the slope and intercept obtained from (9) and the concentration of suspended sediment was figured [22].

\subsection{Results of Estimated Suspended Sediment Concentration}

3.3.1. Static $A D C P$. In Figure 7, it is shown that the concentration of suspended sediment near the seabed was higher than those near the surface and water column. At the dive site area (Figure 7(a)), the highest fluctuation was found at the depth 

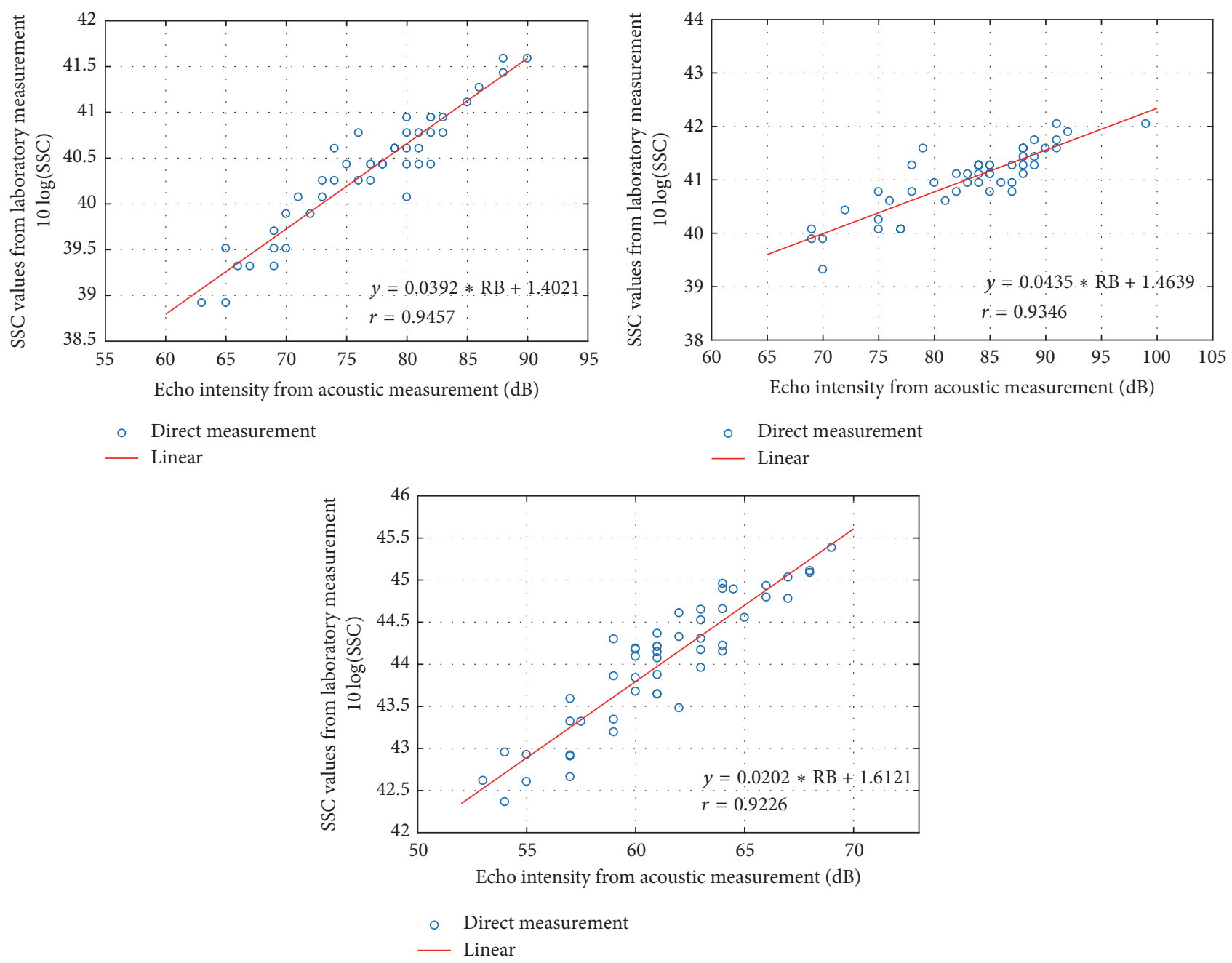

FIGURE 6: Calibration of ADCP relative acoustic backscatter data using the laboratory-analyzed SSC. Each sample was collected in every one hour at different tidal conditions.

between 25 and $30 \mathrm{~m}$. The lowest concentration of suspended sediment in the observed area shown in the echogram was $45 \mathrm{mg} \mathrm{L}^{-1}$ and the highest value was $95 \mathrm{mg} \mathrm{L}^{-1}$. The SSC were different among the locations and likely depended on location. The SSC at shipping lane area was markedly higher (Figure 7(b)) than those at the other locations and the highest concentration was found at $12-16 \mathrm{~m}$.

The suspended sediment material at the water column was composed by substrate material from the seabed, plankton (especially zooplankton), and other floating microorganisms and particles in the water column. Based on the observation, substrate conditions on the seabed at both locations were almost similar, composed by sandy mud and very fine sand [23]. Resuspension of sediment that primarily contributed to the SSC near bottom was possibly due to advection of bottom water. The movement of suspended material was also influenced by the tidal currents.

This area had an average tidal range of $1.2 \mathrm{~m}$ and the tidal pattern was mixed semidiurnal. There were correlations between SSC differences with that tidal condition at high water, low water, ebb tides, and flood tides. The comparison between ebb and flood tides in SSC measurement shows that the concentration varied. It was indicated that the SSC values were lower during flood tide, but the SSC values were higher during ebb tides. For more details, the data in Figure 7 was magnified by only three days' observation time to prove that the SSC was affected by tidal current (Figure 8).

The effect of tidal current to the SSC values was also confirmed by tide phenomenon that occurred periodically. The indication was the tidal caused water mass movement through tidal currents, carrying suspended particles that affected the amount of suspended sediment concentration. During the low water, the SSC values were significantly higher because high amount of suspended sediment was alternatingly eroded, resuspended, and deposited. If the size of sediment was small (e.g., in sandy mud or very fine sand form), the suspended sediment would have higher concentration $[23,24]$. This tidal current affected suspended sediment concentration as an energy source, causing transport of particles. 


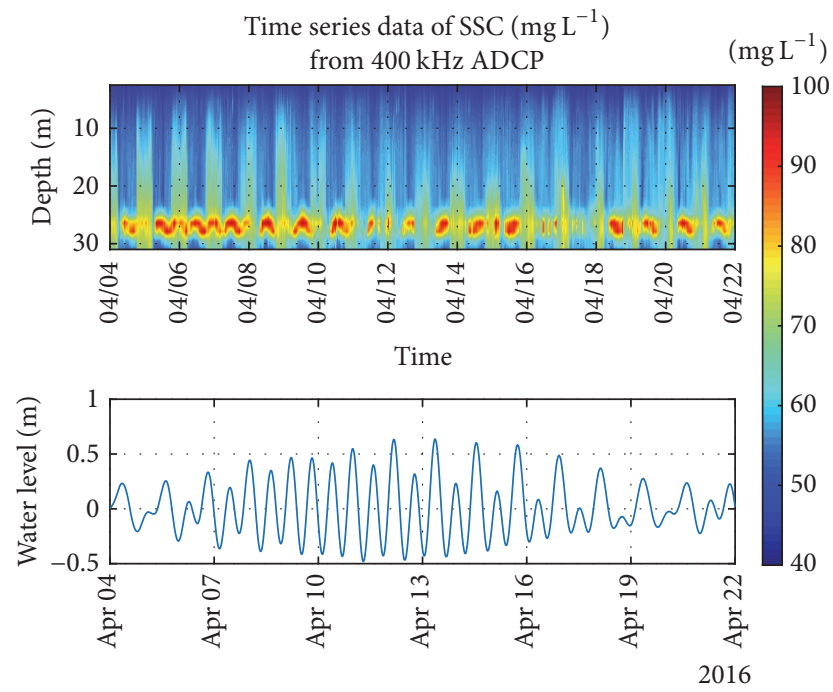

(a)

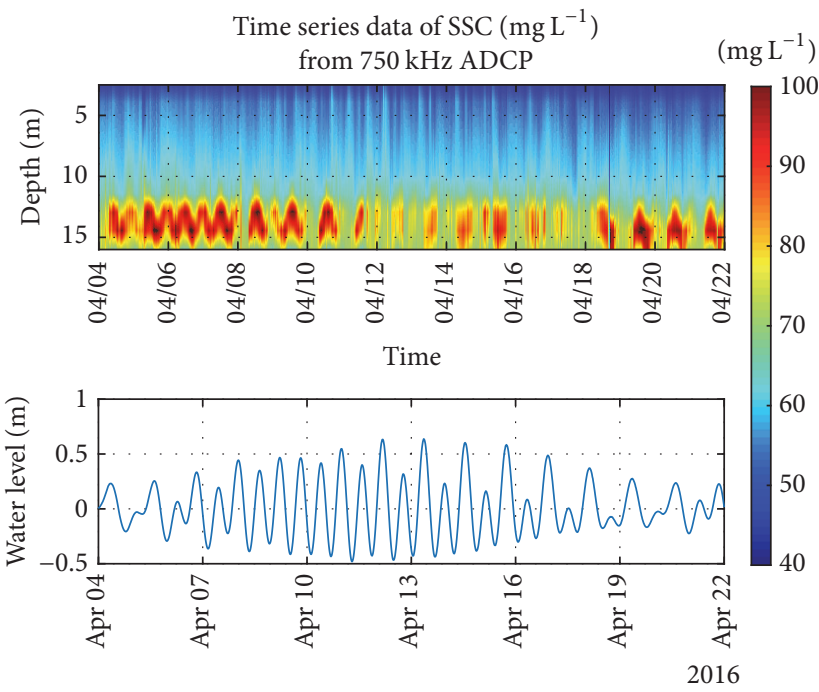

(b)

FIGURE 7: Time series of suspended sediment concentration from static ADCP at (a) dive site area and (b) shipping lane area after acoustic data processing with tidal water level $(\mathrm{m})$ comparison. From this data, it is shown that the upper layer of the water column has lower concentration compared to bottom layer.
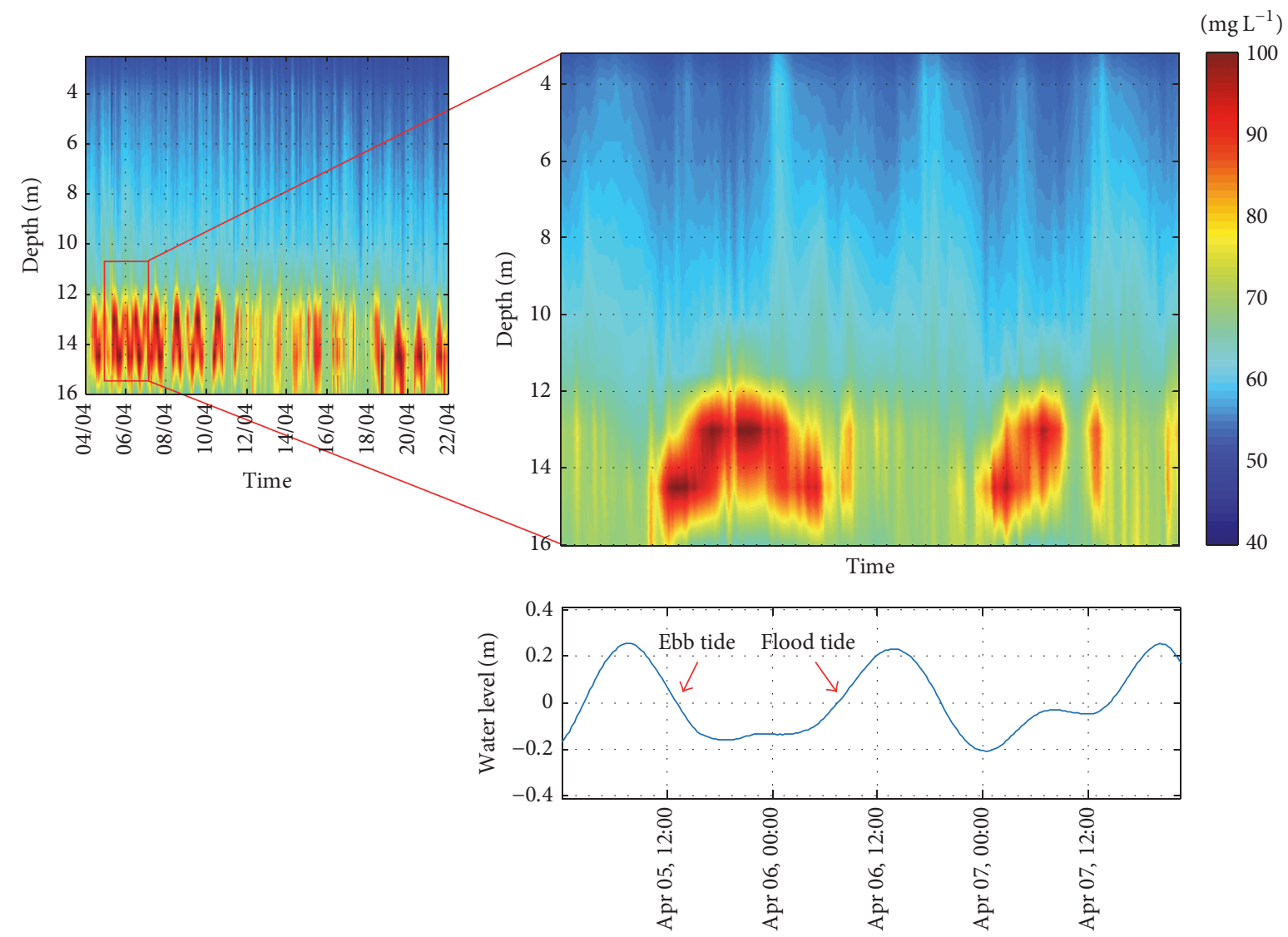

FIGURE 8: The influence of tides on suspended sediment concentration. 

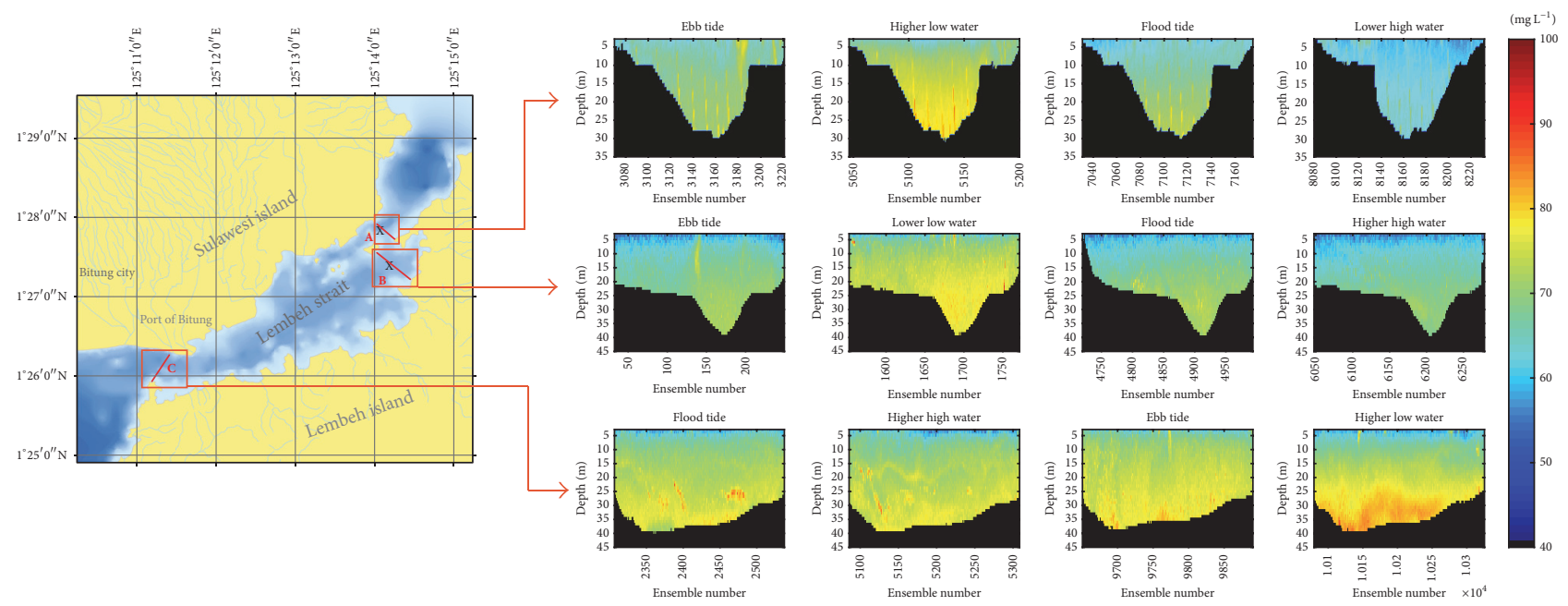

FIGURE 9: Spatial distribution of suspended sediment concentration using the mobile ADCP in three observation areas of Lembeh Strait during four different tidal conditions.

3.3.2. Mobile ADCP. For the mobile method analysis, the averaged data of the surveyed cross-section at different location and tidal time were chosen. The research has previously been performed with various detailed echo intensity at each depth. Field investigations were performed during both high and low tides and also flood and ebb tide cycles in all area. Spatial distributions of average suspended sediment concentration are shown in Figure 9.

Over the cross-section area, the deepest point was around $40 \mathrm{~m}$. Suspended sediment concentration values along Lembeh Strait using mobile method ranged from 45 to $80 \mathrm{mg} \mathrm{L}^{-1}$. The range increased during low tide, which was increased by 10 to $15 \mathrm{mg} \mathrm{L}^{-1}$ in all locations. Comparing all of the sites, spatially, the near port area had the highest concentration of suspended sediment. The reason for the higher SSC values obtained at near port during this research was likely because there was sediment input through inlet from Port of Bitung. Port activities such as dredging and disposal to the water column increased SSC [25]. At the locations of shipping lines and dive site area, the limited supply of suspended sediment from mainland or rivers led to lower concentration when compared to areas near the port.

An important aspect of tidal condition in Lembeh Strait was that the current usually flowed from the southwest to northeast during ebb tide to low water and vice versa during flood tide to high water. During high tide, the volume of water in Lembeh Strait increased and thus reduced the concentration of suspended sediment. The fluctuation patterns of suspended sediment concentration at all locations were relatively similar. Based on Figure 9, during the ebb tide to low water tide, the concentration of suspended sediment was higher, otherwise during the flood tide to high water tide, the concentration of suspended sediment was lower.

Based on static and mobile ADCP measurements, it was proved that suspended sediment variation along Lembeh Strait was affected by tidal condition. Suspended sediment concentration was affected by the types and characteristics of suspended sediment, morphology of bathymetry, seabed sediment, frequency of ADCP instrument, and factors of tidal condition.

\subsubsection{Comparison between ADCP-Based SSC and Laboratory-}

Based SSC. In evaluating the estimation results of the suspended sediment concentration, the correlation between the measurement results of $\mathrm{ADCP}$ to the measurement in the laboratory was required to be identified. Accuracy and precision were considerable factors in the utilization of ADCP for the quantification of suspended sediment, and errors were still found in the calculations [4]; for example, on Figure 10, it shows the distribution of suspended sediment concentration derived from ADCP acoustic intensity and direct measurement. By comparing the 1:1 line to the best fit linear regression line, the ADCP-based SSC estimates were slightly lower than the estimates based on direct measurement. Results of the acoustic method show a good qualitative agreement with statistical relationships between the SSC and direct SSC measurement method with coefficient correlation $(r)>0.8$.

The result of the measurement shows that the estimated concentration of suspended sediment was slightly lower than actual measurement through laboratory analysis which was caused by several factors; for example, there were differences of particle size distribution at various depths as well as differences in sampling intervals. Limitation of ADCP in observing different grain sizes of suspended sediment has been described previously by researcher (e.g., [5]). The ADCP instrument was unable to distinguish between large particle sizes and small particle sizes that accumulate in particular volume in this research, so the measurement using ADCP will be slightly lower in estimating the suspended sediment concentration [26]. However, in other studies different results were found, that is, overestimation in the estuary because of relatively large events on net suspended sediment flux [27]. 

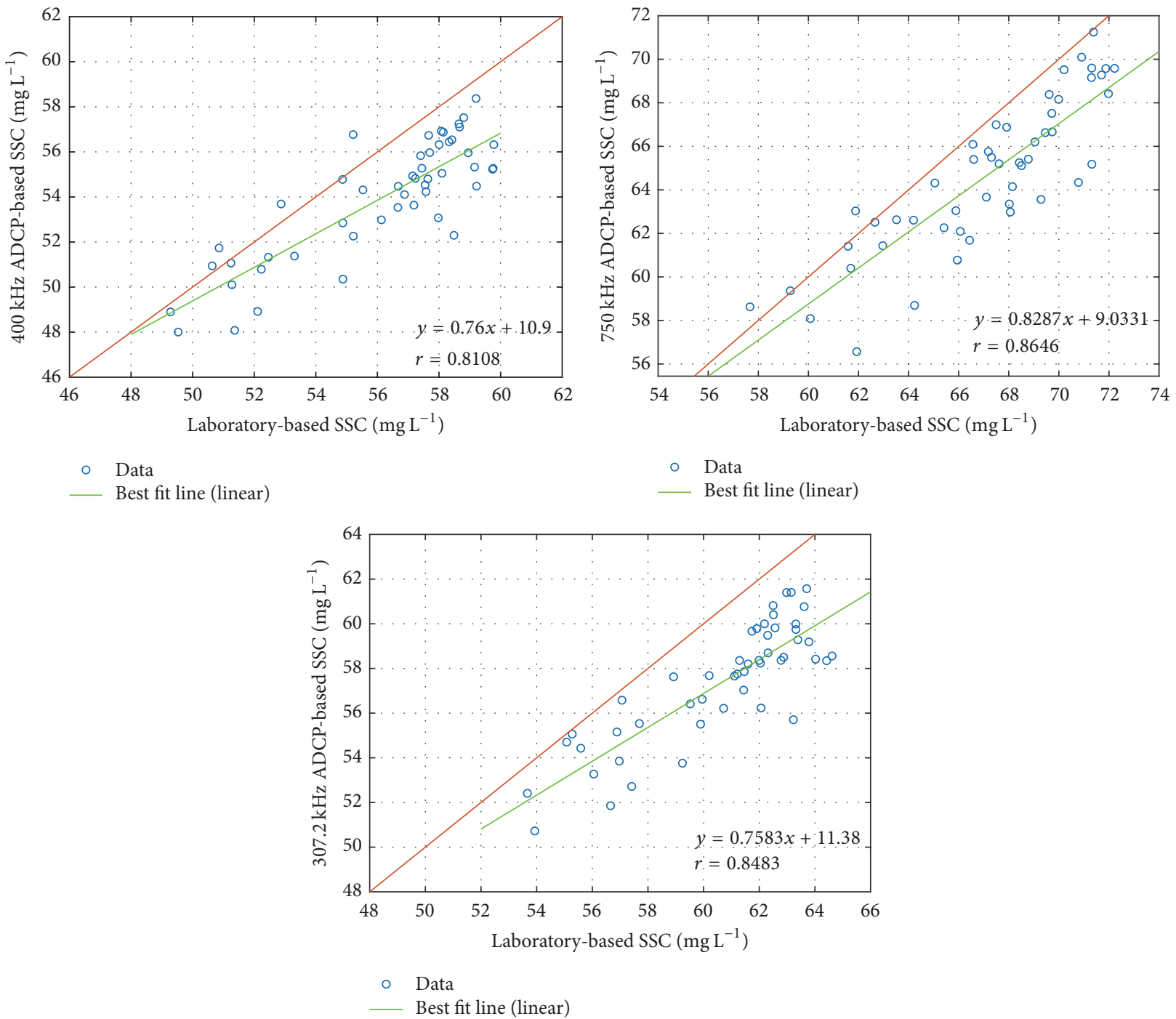

FIGURE 10: Validation of estimated suspended sediment concentrations measured by comparing all ADCP results to the results of laboratory measurements.

3.3.4. Comparison between Static ADCP and Mobile ADCP. Based on the SSC measurement using static and mobile ADCP, it was known that statistically the results obtained from ADCP were not significantly different when compared to laboratory measurements. However, a validation of the results from $\mathrm{ADCP}$ was required by comparing these two methods. During data processing, the mobile and static ADCP coordinates were equated to obtain the same data at one point of the observation area. Factors of data retrieval also needed to be considered. The data in Figure 11 were obtained from the results of ensemble number selection on mobile ADCP RDI Workhorse $307.2 \mathrm{kHz}$ which had the same coordinates as the static ADCP SonTek. A total of 44 ensembles were selected based on the location of the same coordinate points. Intensity data on April 10, 2016, at 10:15 to 14:05 were selected; then the data were transformed into suspended sediment concentration. Figure 11 consists of the time series data of suspended sediment concentration of the static ADCP SonTek on April 10, 2016, for 24 hours and partially collected data from 10:00 to 14:10.

In Figure 11, it is indicated that the SSC results from the two methods had similar characteristic near the bottom of the water with the depth of $12-15 \mathrm{~m}$. The suspended sediment concentration was higher than those of other depths, ranging from 75 to $83 \mathrm{mg} \mathrm{L}^{-1}$. This strengthens the evidence that in the observation area there was stirring of the bottom sediment so at that depth the concentration was higher. At $2-10 \mathrm{~m}$ of depth, the suspended sediment concentration obtained from static ADCP SonTek was slightly higher than that of mobile ADCP. The results obtained from the static ADCP had blue and green colors in echogram and had concentrations ranging from 53 to $58 \mathrm{mg} \mathrm{L}^{-1}$ while the results of the mobile ADCP had darker blue color with the concentration ranging $50-55 \mathrm{mg} \mathrm{L}^{-1}$. This was due to the higher frequency of static ADCP $(750 \mathrm{kHz})$, making it more sensitive to detect smaller particles when compared to mobile ADCP $(307.2 \mathrm{kHz})$. 


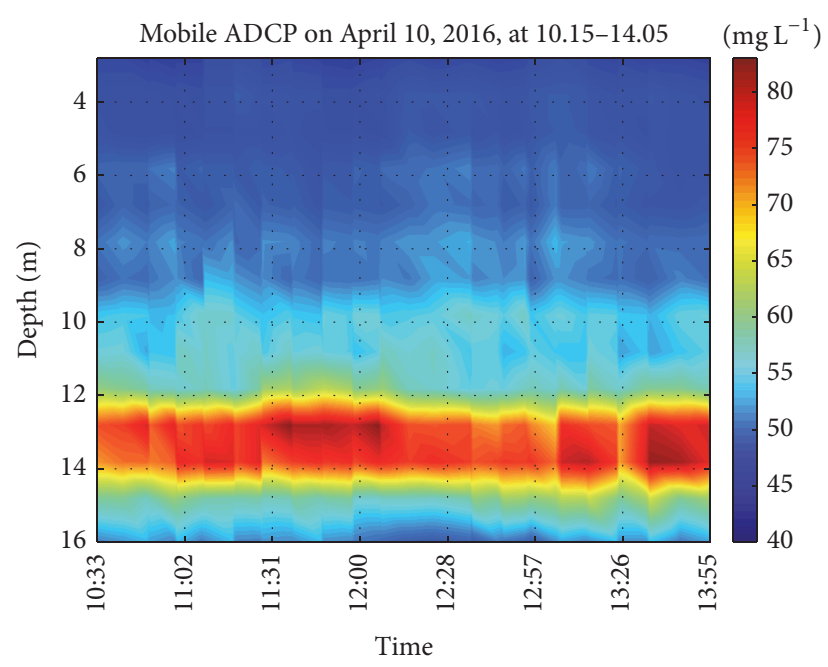

(a)

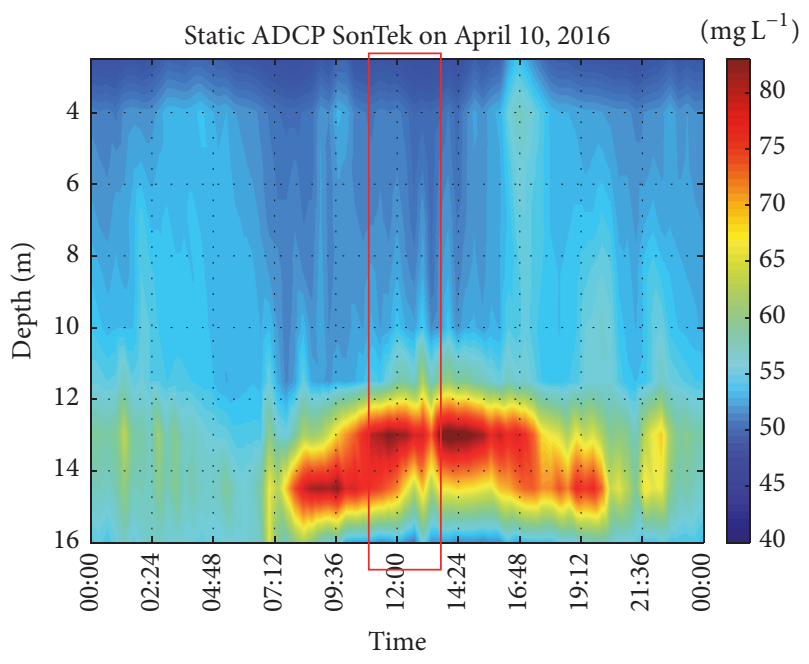

(b)

FIgURE 11: Comparison of SSC results from (a) mobile ADCP RDI $307.2 \mathrm{kHz}$ and (b) static ADCP SonTek $750 \mathrm{kHz}$ on April 10, 2016.

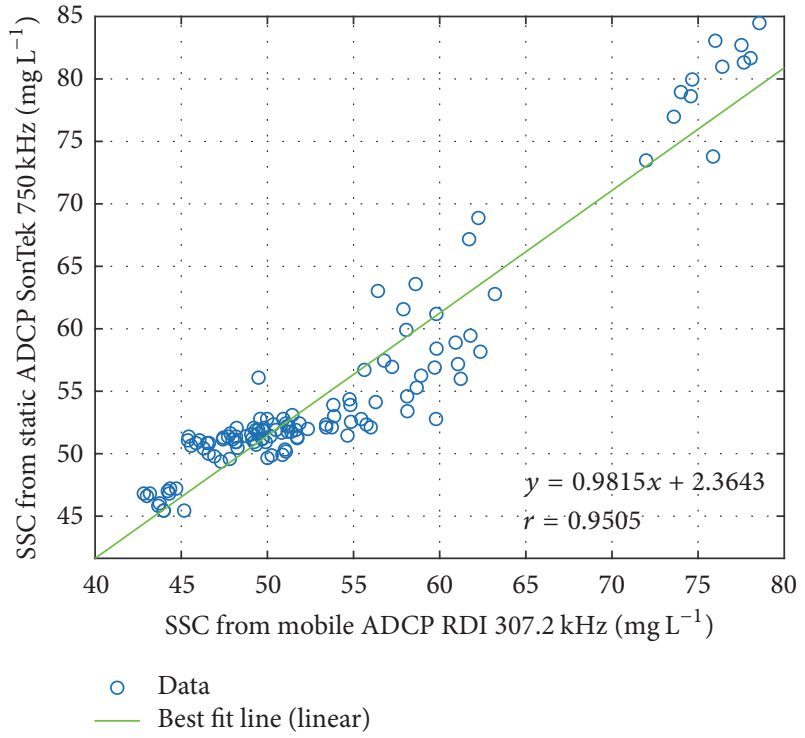

FIGURE 12: Comparison of SSC values obtained from mobile ADCP RDI $307.2 \mathrm{kHz}$ and static ADCP SonTek $750 \mathrm{kHz}$ at the same coordinates and time.

Because of its high sensitivity, the static ADCP was able to quantify smaller sediments, thereby affecting the intensity of the echo reversing back into the transducer to be higher. The suspended sediment concentration in Figure 11 was then extracted and plotted to analyze the error between static and mobile ADCP methods.

Based on the results of the analysis in Figure 12, the highest suspended sediment concentration indicated by reddishyellow color was found in the $25-30 \mathrm{~m}$ depth range with the concentration of $70-80 \mathrm{mg} \mathrm{L}^{-1}$ (Figure 13). This result also proves that there was a suspended sediment stirring process in this area as well. At the depth of 2 to $23 \mathrm{~m}$, the concentration of suspended sediments tended to be the same. This was because the frequencies used in the static and mobile ADCP were not much different ( 400 and $307.2 \mathrm{kHz}$ ). The result of data processing of suspended sediment concentration was then extracted and plotted using MATLAB.

In determining the suitable data retrieval method using ADCP for monitoring suspended sediment concentration in a region, things to consider were data factors provided by ADCP. If the time series data was to be obtained, then static ADCP method had to be selected. However, if the distribution of sediment concentration available in an area was required, the mobile ADCP method could be used [28]. From the results of the study (Figures 11 and 13) it can be seen that both data retrieval methods using ADCP were equally good. The comparison of results obtained from static and mobile methods shows a close relationship with the correlation coefficient, with $(r) 0.95$. What was needed to be considered, however, was the frequency of the ADCP tool used for the detection and quantification of suspended sediment.

The plot result involved 340 data items with slope and intercept values of 0.9488 and 2.1558. The resulting correlation coefficient $(r)$ had a value of 0.9545 (Figure 14), greater than the comparison between static ADCP SonTek and mobile ADCP RDI. This might be due to frequencies that did not vary much in the static ADCP Nortek $(400 \mathrm{kHz})$ and the mobile ADCP RDI $(307.2 \mathrm{kHz})$, unlike SonTek which had a frequency of $750 \mathrm{kHz}$ compared to RDI's $307.2 \mathrm{kHz}$. From this finding, it can also be indicated that the results obtained from the static ADCP and the mobile ADCP measurements had a close relationship.

\section{Conclusion}

The intensity echo value (EI) obtained from the ADCP instrument could be converted to suspended sediment concentration based on sonar equations. The results showed that suspended sediment concentration in the Bitung Port 


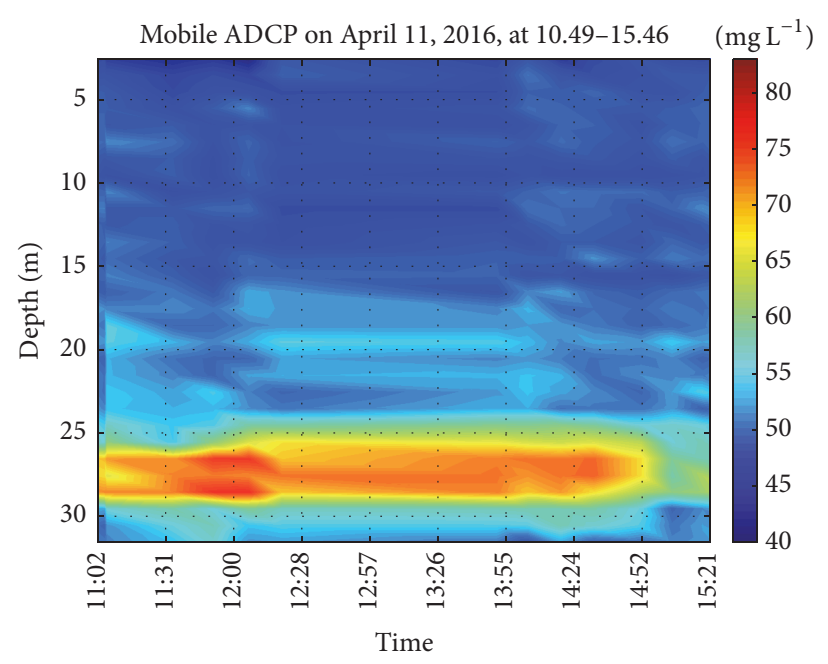

(a)

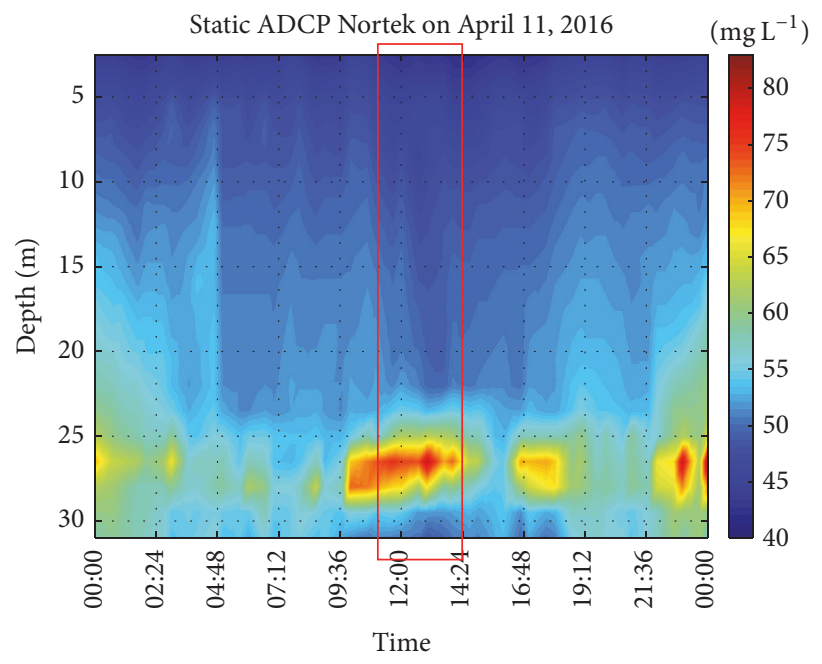

(b)

FIGURE 13: Comparison of SSC results from (a) mobile ADCP RDI $307.2 \mathrm{kHz}$ and (b) static ADC $400 \mathrm{kHz}$ on April 11, 2016.

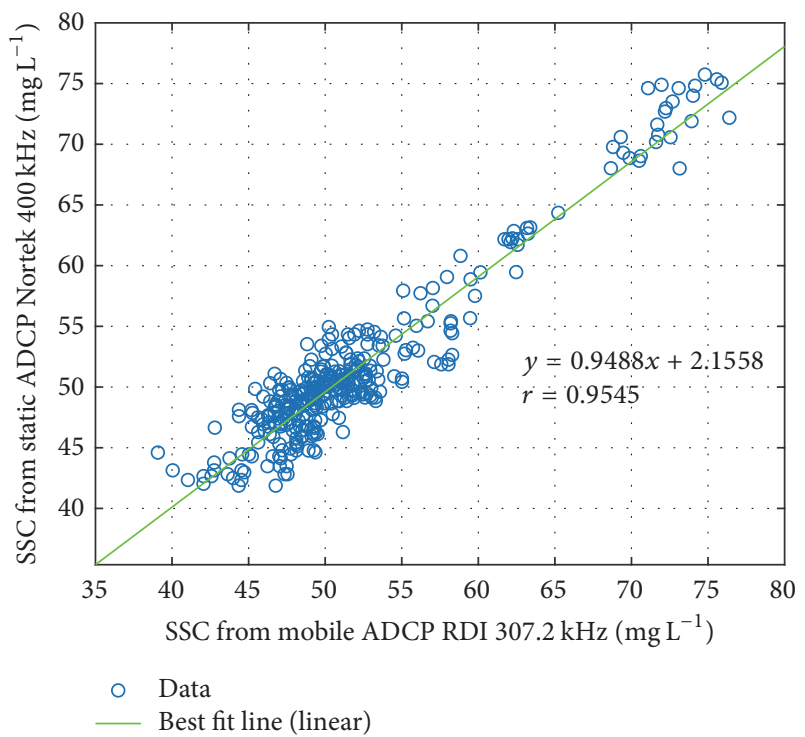

FIGURE 14: Comparison of SSC values obtained from mobile ADCP RDI $307.2 \mathrm{kHz}$ and static ADC $400 \mathrm{kHz}$ at the same coordinates and time.

area was the highest, which was caused by input from the mainland. The highest suspended sediment concentrations in all locations were located near the bottom especially in areas that had a central slope at the bottom of the strait. The combination of static and mobile ADCP methods for quantification of suspended sediments in Lembeh Strait waters provided good data and could be used as a tool in monitoring sediment transport. Tidal and low tide factors influenced the concentration of suspended sediment.

Further research is needed on the acoustic response of static and mobile ADCP based on the particle size and suspended sediment in the water column. This needs to be performed in order to determine the concentration of suspended sediment of each size and type.

\section{Conflicts of Interest}

The authors declare that there are no conflicts of interest.

\section{Acknowledgments}

The authors would like to acknowledge the Directorate General of Higher Education (DIKTI), Indonesia, for financially supporting this research through PMDSU Research Grant Scheme (no. 330/SP2H/LT/DRPM/IX/2016 and no. 136/SP2H/LT/DRPM/IV/2017). This work is also supported by Marine Geological Institute, Ministry of Energy and Mineral Resources, Bandung, Indonesia.

\section{References}

[1] H.-B. Park and G.-H. Lee, "Evaluation of ADCP backscatter inversion to suspended sediment concentration in estuarine environments," Ocean Science Journal, vol. 51, no. 1, pp. 109-125, 2016.

[2] C. Tessier, P. Le Hir, X. Lurton, and P. Castaing, "Estimation of suspended sediment concentration from backscatter intensity of Acoustic Doppler Current Profiler," Comptes Rendus - Geoscience, vol. 340, no. 1, pp. 57-67, 2008.

[3] S. A. Moore, J. Le Coz, D. Hurther, and A. Paquier, "On the application of horizontal ADCPs to suspended sediment transport surveys in rivers," Continental Shelf Research, vol. 46, pp. 50-63, 2012.

[4] M. Guerrero, N. Rüther, S. Haun, and S. Baranya, "A combined use of acoustic and optical devices to investigate suspended sediment in rivers," Advances in Water Resources, vol. 102, pp. $1-12,2017$.

[5] A. K. Rai and A. Kumar, "Continuous measurement of suspended sediment concentration: Technological advancement and future outlook," Measurement, vol. 76, pp. 209-227, 2015. 
[6] C. Sahin, R. Verney, A. Sheremet, and G. Voulgaris, "Acoustic backscatter by suspended cohesive sediments: Field observations, Seine Estuary, France," Continental Shelf Research, vol. 134, pp. 39-51, 2017.

[7] J. W. Gartner, "Estimating suspended solids concentrations from backscatter intensity measured by acoustic Doppler current profiler in San Francisco Bay, California," Marine Geology, vol. 211, no. 3-4, pp. 169-187, 2004.

[8] D. Felix, I. Albayrak, and R. M. Boes, "Continuous measurement of suspended sediment concentration: Discussion of four techniques," Measurement, vol. 89, pp. 44-47, 2016.

[9] S. Haun, N. Rüther, S. Baranya, and M. Guerrero, "Comparison of real time suspended sediment transport measurements in river environment by LISST instruments in stationary and moving operation mode," Flow Measurement and Instrumentation, vol. 41, pp. 10-17, 2015.

[10] Poerbandono and T. Suprijo, "Modification of attenuation rate in range normalization of echo levels for obtaining frequencydependent intensity data from $0.6 \mathrm{MHz}$ and $1.0 \mathrm{MHz}$ devices," Journal of Engineering and Technological Sciences, vol. 45, no. 2, pp. 140-152, 2013.

[11] K. L. Deines, "Backscatter estimation using broadband acoustic Doppler current profilers," in Proceedings of the 1999 IEEE 6th Working Conference on Current Measurement, pp. 249-253, March 1999.

[12] S. Jiang, T. D. Dickey, D. K. Steinberg, and L. P. Madin, "Temporal variability of zooplankton biomass from ADCP backscatter time series data at the Bermuda Testbed Mooring site," Deep-Sea Research Part I: Oceanographic Research Papers, vol. 54, no. 4, pp. 608-636, 2007.

[13] P. Ghaffari, J. Azizpour, M. Noranian, V. Chegini, V. Tavakoli, and M. Shah-Hosseini, "Estimating suspended sediment concentrations using a broadband ADCP in Mahshahr tidal channel," Ocean Science Discussions, vol. 8, no. 4, pp. 1601-1630, 2011.

[14] P. Gruber, D. Felix, G. Storti, M. Lattuada, P. Fleckenstein, and F. Deschwanden, "Acoustic measuring techniques for suspended sediment," in Proceedings of the IOP Conference Series: Earth and Environmental Science, vol. 49, no. 122003, pp. 1-11, 2016.

[15] M. N. Landers, Fluvial Suspended Sediment Characteristics by High-Resolution, Surrogate Metrics of Turbidity, LaserDiffraction, Acoustic Backscatter, and Acoustic Attenuation, Georgia Institute of Technology, 2012.

[16] S. Baranya and J. Józsa, "Estimation of suspended sediment concentrations with ADCP in danube river," Journal of Hydrology and Hydromechanics, vol. 61, no. 3, pp. 232-240, 2013.

[17] American Public Health Association, Standard Methods for the Examination of Water and Wastewater, APHA, 22nd edition, 2012.

[18] M. Guerrero, R. N. Szupiany, and M. Amsler, "Comparison of acoustic backscattering techniques for suspended sediments investigation," Flow Measurement and Instrumentation, vol. 22, no. 5, pp. 392-401, 2011.

[19] F. Jourdin, C. Tessier, P. L. Hir et al., "Dual-frequency ADCPs measuring turbidity," Geo-Marine Letters, vol. 34, no. 4, pp. 381397, 2014.

[20] M. G. Sassi, A. J. F. Hoitink, and B. Vermeulen, "Impact of sound attenuation by suspended sediment on ADCP backscatter calibrations," Water Resources Research, vol. 48, no. 9, pp. 1-14, 2012.

[21] A. Dwinovantyo, H. M. Manik, T. Prartono et al., "Estimation of suspended sediment concentration from Acoustic Doppler
Current Profiler (ADCP) instrument: A case study of Lembeh Strait, North Sulawesi," in Proceedings of the IOP Conference Series: Earth and Environmental Science, vol. 54, no. 012082, pp. $1-8,2017$.

[22] V. B. Piotukh, A. G. Zatsepin, and S. B. Kuklev, "Amplitude calibration of an acoustic backscattered signal from a bottommoored ADCP based on long-term measurement series," Oceanology, vol. 57, no. 3, pp. 455-464, 2017.

[23] S. Solikin, H. M. Manik, S. Pujiyati, and S. Susilohadi, "Pemrosesan Sinyal Data Sub-bottom Profiler Substrat Dasar Perairan Selat Lembeh," Jurnal Rekayasa Elektrika, vol. 13, no. 1, pp. 4247, 2017.

[24] J. Xiong, X. H. Wang, Y. P. Wang et al., "Mechanisms of maintaining high suspended sediment concentration over tidedominated offshore shoals in the southern Yellow Sea," Estuarine, Coastal and Shelf Science, vol. 191, pp. 221-233, 2017.

[25] X. Liu, X. L. Feng, and J. Liu, "Characteristics of suspended sediment and resuspension process in Wendeng coastal area, Shandong peninsula," Advanced Materials Research, vol. 807809, pp. 1595-1599, 2013.

[26] G. W. Wilson and A. E. Hay, "Acoustic backscatter inversion for suspended sediment concentration and size: A new approach using statistical inverse theory," Continental Shelf Research, vol. 106, pp. 130-139, 2015.

[27] M. A. Downing-Kunz and D. H. Schoellhamer, "Seasonal variations in suspended-sediment dynamics in the tidal reach of an estuarine tributary," Marine Geology, vol. 345, pp. 314-326, 2013.

[28] J. J. Nauw, L. M. Merckelbach, H. Ridderinkhof, and H. M. van Aken, "Long-term ferry-based observations of the suspended sediment fluxes through the Marsdiep inlet using acoustic Doppler current profilers," Journal of Sea Research, vol. 87, pp. 17-29, 2014. 


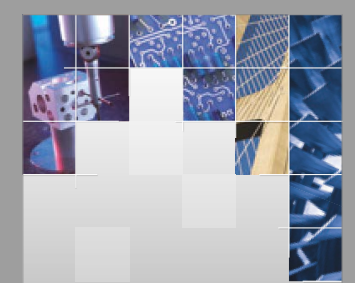

\section{Enfincering}
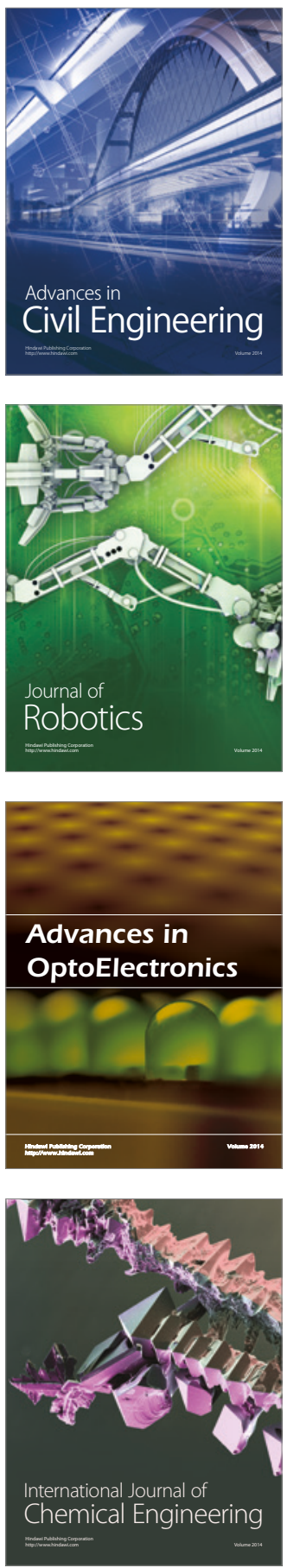

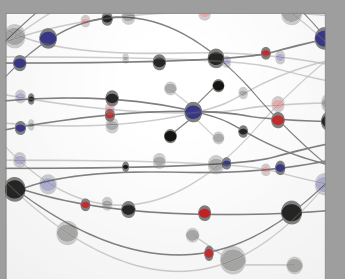

The Scientific World Journal

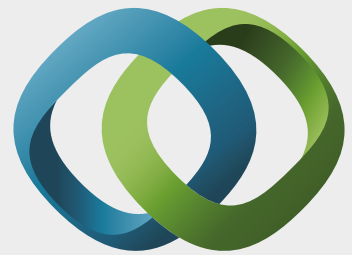

\section{Hindawi}

Submit your manuscripts at

https://www.hindawi.com
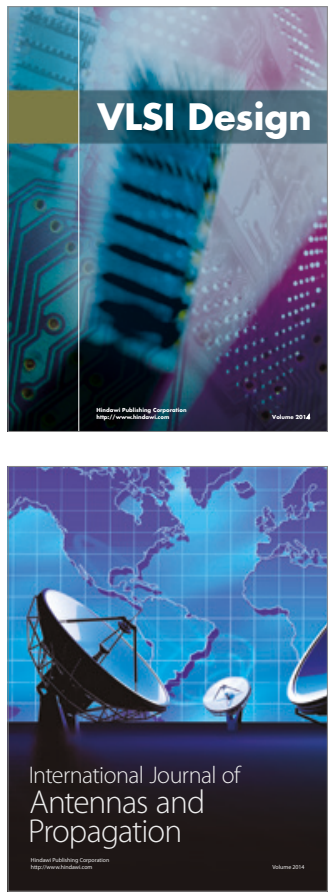

\section{Rotating}

Machinery
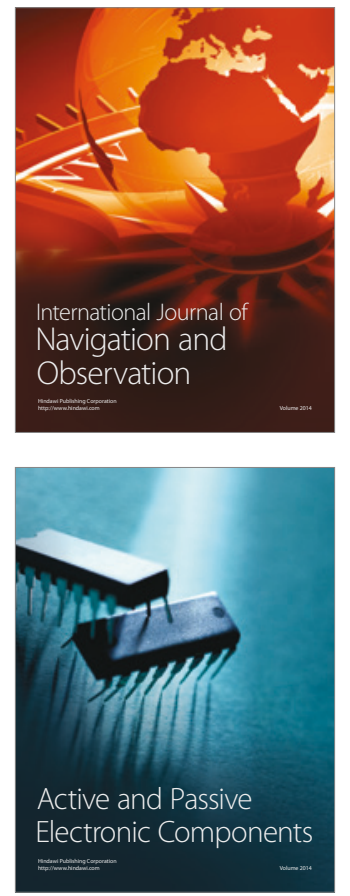
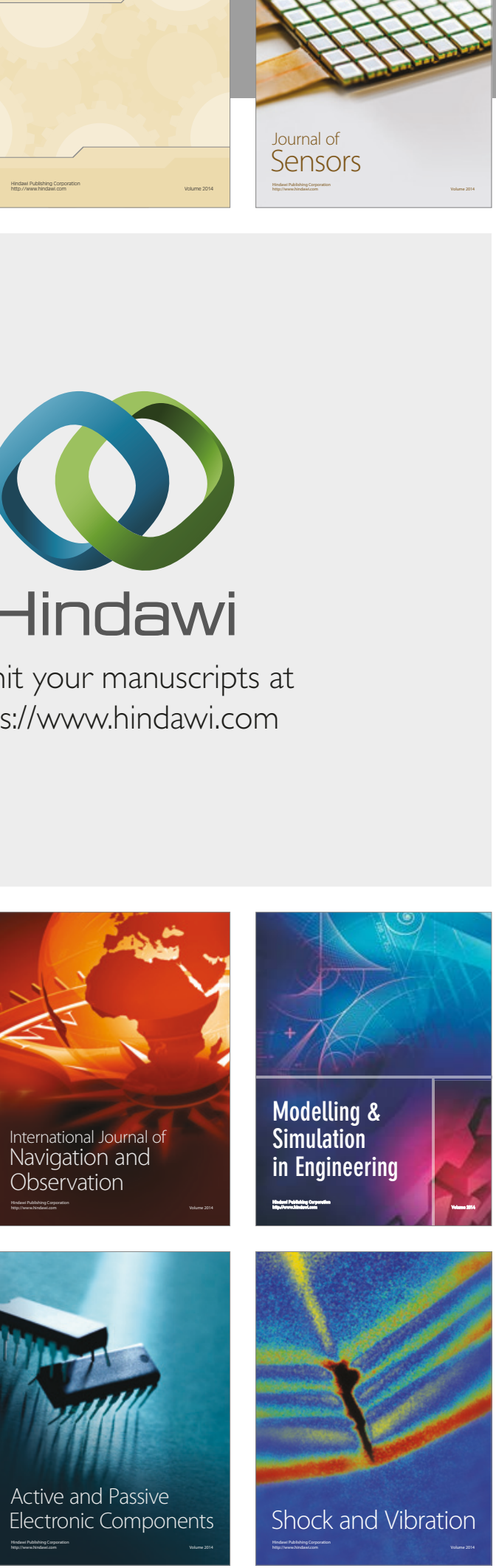
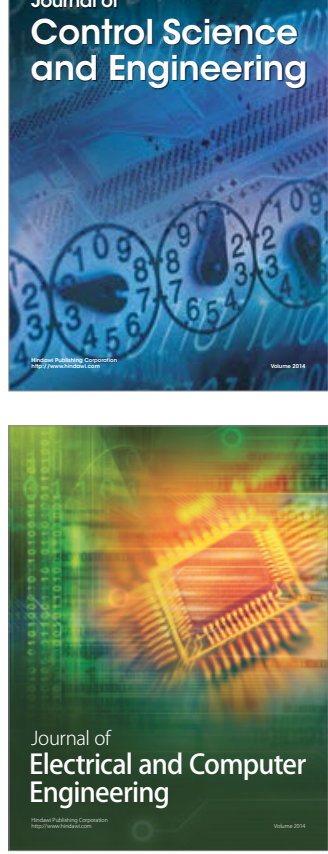

Distributed

Journal of

Control Science

and Engineering
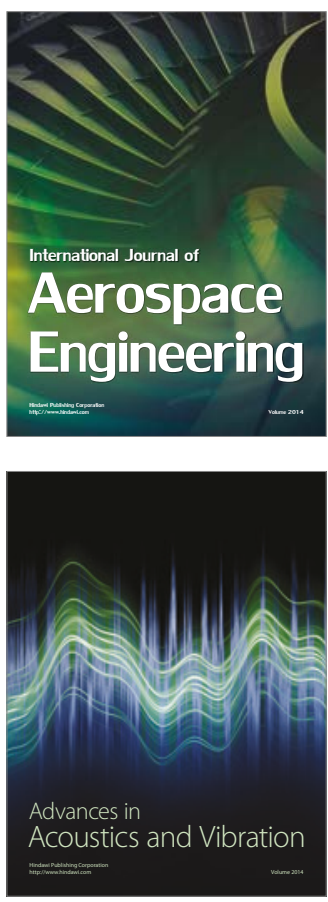

Sensor Networks 